\title{
RELAÇÕES ENTRE ESCOLA- FAMÍLIA-COMUNIDADE COMO MECANISMO POTENCIALIZADOR DA APRENDIZAGEM DISCENTE NOS ANOS INICIAIS NA ESCOLA PÚBLICA
}

\begin{abstract}
Géssica Galdino da Silva Pereira, Universidade Federal de Campina Grande (UFCG), galdino.gessica366@gmail.com
\end{abstract}

Wiama de Jesus Freitas Lopes, Universidade Federal de Campina Grande (UFCG), uiama@uol.com.br

\section{RESUMO}

Este trabalho intenciona analisar os mecanismos de gestão em prol da necessária articulação escola-família-comunidade em função de efetivas estratégias de aprendizagens discentes nos primeiros anos de escolarização. O que se delineia a partir da seguinte questão de pesquisa: De que modo a escola pública pode articular a relação escola-família-comunidade em função das estratégias de aprendizagens discentes nos anos iniciais? A pesquisa empírica envidada nesse estudo se deu por intermédio da abordagem qualitativa e com categorização simples dos dados por termos recorrentes. $\mathrm{O}$ que subsidiou as análises aqui desenvolvidas a partir de estudo exploratório envolvendo nove entrevistas semiestruturada, com quatro professoras do fundamental I, uma gestora e quatro mães de alunos pertencentes ao conselho escolar da unidade educacional que sediou a parte empírica da etapa de investigação desse estudo. As principais fontes de fundamentação desse estudo foram empreendidas a partir das produções a cerca da interação escola família UNESCO (2009) e _participação em Paro (2008). Assim, chegou-se a algumas conclusões nesse estudo quanto à necessidade de fomentar a participação da família em diálogos no e para o fortalecimento da cultura de acompanhamento do rendimento escolar dos discentes em seus processos de formação humana corroborado pela escola.

PALAVRAS-CHAVE: Interação escola-família-comunidade. Gestão de aprendizagens discentes. Escola Pública.

\section{ABSTRACT}

This work called and, as it overall goal, intents to analyze the mechanisms of management in favor of the link with school-family-community in according to effective strategies of students learning in the early years of the public school. What is delineated from the following research question: How does the public school can articulate the school-family- 
community relationship in terms of students learning strategies in the early years? Empirical research taken in this study occurred through qualitative approach, with semi-structured interviews and simple categorization of data for recurring terms. What contributed to the analyses developed here from exploratory study involving nine semi-structured interviews with primary teachers, a manager and four student's mother belonging to the school council of the educational unit that hosted the empirical part of the field research phase of this study. The main sources of reasoning of this study was taken from the UNESCO family interaction school production (2009); participation and Paro (2008). Thus, reached some conclusions in this study as the need to promote family participation in dialogues and to strengthen the follow-up culture of academic performance of the students in their human development processes supported by the school.

Keywords: Interaction school-family-community. Student learning management. Public school.

\section{RESUMEN}

Este trabajo pretende analizar los mecanismos de gestión en pro de la necesaria articulación escuela-familia-comunidad en función de efectivas estrategias de aprendizajes discentes en los primeros años de escolarización. Lo que se delinea a partir de la siguiente cuestión de investigación: ¿De qué modo la escuela pública puede articular la relación escuela-familia-comunidad en función de las estrategias de aprendizajes discentes en los años iniciales? La investigación empírica envíada en ese estudio se dio por medio del abordaje cualitativo y con categorización simple de los datos por términos recurrentes. Lo que subsidió los análisis aquí desarrollados a partir de un estudio exploratorio que involucra nueve entrevistas semiestructuradas, con cuatro profesoras del fundamental I, una gestora y cuatro madres de alumnos pertenecientes al consejo escolar de la unidad educativa que sedujo la parte empírica de la etapa de investigación de ese estudio. Las principales fuentes de fundamentación de este estudio fueron emprendidas a partir de las producciones a cerca de la interacción escuela familia UNESCO (2009) y participación en Paro (2008). Así, se llegó a algunas conclusiones en ese estudio en cuanto a la necesidad de fomentar la participación de 
la familia en diálogos en y para el fortalecimiento de la cultura de seguimiento del rendimiento escolar de los discentes en sus procesos de formación humana corroborados por la escuela.

PALABRAS CLAVE: Interacción escuela-familia-comunidad. Gestión de aprendizajes discentes. Escuela pública.

\section{INTRODUÇÃO}

Este trabalho tem por objetivo analisar os mecanismos da gestão em prol da articulação escola-família-comunidade em função de efetivas estratégias de aprendizagens nos anos iniciais na escola pública. Preponderantemente atrelada ao ensino e aprendizagem, à literatura educacional contemporânea evidencia com especial atenção a necessidade de se pensar pedagogicamente às relações para com a família, tendo em vista a consolidação tanto da aprendizagem individual, quanto da formação humana que se pretende estimular nos educandos em prol de formativos processos de socialização. Sobretudo em um cenário cuja aprendizagem deve sempre ser compreendida como processo multidimensional que não abrange tão somente a produção do trabalho pedagógico do professor restrita à sala de aula.

Para delimitar a discussão sobre a análise dos mecanismos da gestão escolar no que concerne a interação entre a escola e a família deve-se, como um dos objetivos específicos discorrer acerca da importância da relação escola-família-comunidade frente ao processo de desenvolvimento da aprendizagem dos educandos. Uma vez que os alunos/filhos, exceto aqueles que estudam em tempo integral, passam a maior parte do dia envolvidos no seio familiar, partilhando conhecimentos e experiências de base valorativa/formativa.

Para esta reflexão, a parte empírica do estudo teve uma incursão em campo de investigação em que foi possível analisar, por uma abordagem qualitativa, com estudos exploratórios e entrevista semiestruturada a seguinte questão de pesquisa: De que modo a escola pública pode articular a relação escola-família-comunidade em função das estratégias de aprendizagens nos anos iniciais? Para tanto, como locus de pesquisa selecionou-se uma escola pública de ensino fundamental no município de Ipaumirim-CE, devido a proximidade geográfica da residência da pesquisadora e pelo contato já empreendido com equipes docentes 
e técnicas por intermédio de uma passagem em atividade profissional do quadro de servidores da referida escola. Vale ressaltar que dos nove sujeitos entrevistados, 4 são professoras do fundamental I, 1 gestora e 4 mães pertencentes ao Conselho Escolar identificadas ao longo da entrevista com seus respectivos pseudônimos a fim de manter suas identidades em sigilo.

Apesar de todo o contexto institucional estabelecer normas e regulamentações de incentivo a relação escola-família-comunidade, a democratização da escola pública que envolve as relações dialógicas, no que concerne a participação pedagógica e política da família, ainda padece de muitos desafios. Ora internos a instituição, ora externos, extrapolando as competências profissionais das equipes docentes e de dirigentes escolares. Isso, pela fragilidade da cultura de acompanhamento dos filhos na escola, por parte dos pais —, sendo eles de camadas populares ou não — - O que é outro problema a ser pensado e enfrentado pelos profissionais da educação atentos à relação escola-família-comunidade. Internamente, a relação entre os contextos recíprocos aos alunos nos anos iniciais, padece de um retrocesso nas práticas de ensino quando não alinhadas por um bom Plano Municipal de Educação ou quando não pensadas e incorporadas para e no planejamento coletivo desenvolvido na Unidade Escolar.

Fundamentalmente imprescindível à existência e/ou manutenção da relação escolafamília-comunidade, a reflexão sobre o fortalecimento de uma cultura escolar participativa com base em estruturas coletivas esta presente nesse estudo por duas razões mediadoras: a) frente a necessidade da participação política da família nas tomadas de decisão que canalizam esforços de aprendizagem por parte dos alunos/filhos e como a escola deve conduzir suas atividades educativas para consolidar e/ou oportunizar essa participação entre profissionais educadores e co-educadores. Uma vez que a questão da participação pedagógica da família é uma realidade muito aquém das escolas brasileira; b) $\mathrm{O}$ conhecimento do contexto social do aluno, rumo a uma provável negociação e corresponsabilidade mútua na aprendizagem. É com embasamento nestes novos paradigmas democráticos, que fundamentam-se a abrangência sobre a realidade da escola pública e os processos que a organizam afim de adequações de suas práticas pedagógicas e, nesse sentido, a relação para com a família é imprescindível.

Desse modo, a produção aqui delineada tem foco no levantamento e circunscrição de ações educativas que aportem melhores resultados de aprendizagem para os educandos, tendo 
a referência da família como possibilidade de potencialização do trabalho de escolarização de crescente qualidade desafiador de/em nossas escolas.

\subsection{A PARTICIPAÇÃO DA FAMÍLIA NO PROCESSO DE DESENVOLVIMENTO DA APRENDIZAGEM DOS ALUNOS NOS ANOS INICIAIS E SUA RELAÇÃO COM A GESTÃO DA ESCOLA PÚBLICA}

Estando no centro do estudo a aprendizagem dos alunos nos anos inicias, a relação escolafamília-comunidade na escola pública, circunscreve-se no contexto da gestão participativa como prática descentralizada e politizada nos processos sociopolíticos-cultural-educacional dos educados. A abordagem do trabalho da gestão com a participação dos segmentos da escola e da família evidencia as mudanças que se conferem na sociedade atual e que a escola como organização social do trabalho tem que articular na e para essa interação, tendo em vista o rendimento de sua função social de fomentar o desenvolvimento de potencialidades cognitivas, afetivas e motoras de seus educandos no processo educativo.

Sabe-se que a responsabilidade pelo peso educativo dos educandos incide moralmente e legalmente sobre a escola e a família. Nessa perspectiva, a edificação da tão ambicionada participação dos familiares na escola e na vida escolar dos alunos passa ser vista como parte constituinte do trabalho de planejamento educacional, enfatizando nesse dinamismo que quando a escola como sistema aberto desenvolve e/ ou amplia seus conhecimentos e compreensão sobre os educandos, suas competências de comunicação e adequação das estratégias didáticas e/ou pedagógicas aumentam, e, em decorrência, alargam-se as oportunidades de um trabalho escolar participativo bem-sucedido. Haja vista que,

[...] as crianças que chegam à escola são membros-dependentes de um núcleo familiar que lhes dá um nome e um lugar no mundo. Os professores, conectados ou não com o lugar social deste aluno, têm como principal função garantir o direito educacional de cada menino e menina, guiando-se pelas diretrizes do sistema/estabelecimento de ensino com o qual tem vínculo de trabalho. O conjunto de professores, funcionários, coordenadores pedagógicos, diretores escolares e familiares configura uma comunidade escolar, que tem funções deliberativas sobre os vários aspectos e projetos da escola (UNESCO, 2009, p.14.) 
No contexto familiar a criança é filho/ou filha no contexto escolar tal filho/ou filha é discente, havendo dessa forma uma passagem entre um contexto social recíproco ao aluno a um ambiente institucional, em que o professor tem a responsabilidade de conduzir a sistematização do saber histórico e a família o dever de matricular e enviar as crianças à escola. Diante da transição do filho ao aluno a $\operatorname{UNESCO}(2009$, p.14) discute a necessidade em optar por uma abordagem relacional entre "educação e contexto social. Sempre com foco nos processos de ensino-aprendizagem, [...] as relações professor-aluno em uma perspectiva [...] de relações que está por trás e entre esses atores". Discorrer acerca da importância da relação escola-família no processo de aprendizagem dos educandos nos anos iniciais, implica nessas relações sociais uma interpretação multidisciplinar sociológica, antropológica e pedagógica. Mas por tratar-se de um objeto de estudo da sociologia contemporânea, discorrera-se essa relação com ênfase sob esse campo de estudo, ajustando-o as ciências sociais, mais especificamente a Pedagogia e, fundamentalmente, os desafios a tal interação no âmbito da gestão escolar.

A partir da década de 1990, o sistema educacional brasileiro incorporando imediatos reflexos das modificações técnico-organizativas dos modos de produção vigente nos países capitalistas, da nova divisão transacional do trabalho e da intelectualidade das atividades sofreu transformações em suas orientações educativas organizacionais em âmbito federal, estadual e municipal, decorrente da participação do País na Conferência Mundial de Educação para Todos, realizada naquele momento, em Jontiem, na Tailândia e na Declaração de Nova Delhi de Dezembro de 1993.

$\mathrm{O}$ atendimento à demanda de universalização do ensino básico tratou de instruir ao sistema de ensino brasileiro uma série de presunções que em conjunto convergem para o reordenamento da política de gestão educacional no ensino público, instituindo formas mais flexíveis, participativas de administração dos recursos e dos encargos e, fundamentalmente, de tecnologias para se gerir a dinâmica do processo de aprendizagem dos discentes.

Para Freitas (1998) é na totalidade dessas alternativas e motivada por essas realidades que formula-se a política educacional brasileira e sua implementação, sendo nesse contexto determinados consenso mundial, regional e nacional relativa a função contemporânea da educação, sobre as analogias Estado/Sociedade/Educação, bem como diretrizes e recomendações quanto à política e à gestão educacional. 
Segundo Bordignon e Gracindo (2004, p. 147) “a gestão transforma metas e objetivos educacionais em ações, dando concretude ás direções traçadas pelas políticas". A escola pública e sua relação com a família e comunidade, mantida por laços educativos desde o início do processo de escolarização encontra respaldo tanto nos novos modelos de administração escolar (PARO, 2008; LIBÂNEO, 2015; SANDER, 1982) quanto nas políticas públicas a partir do contexto educacional, de conceitos de sistemas e gestão escolar.

Segundo parte do sistema público de ensino, responsável primário pela educação, os objetivo finais referente à educação e o processo educativo nos anos iniciais, tomando por base a LDB 9394/96 preconiza: I - O desenvolvimento da capacidade da aprender, tendo como meios básicos o pleno domínio da leitura, da escrita e do cálculo; II - A compreensão do ambiente natural e social, do sistema político, da tecnologia, das artes e dos valores em que se fundamenta a sociedade; III - O desenvolvimento da capacidade de aprendizagem, tendo em vista a aquisição de conhecimentos e habilidades e a formação de atitudes e valores; IV - O fortalecimento dos vínculos de família, dos laços de solidariedade humana e de tolerância recíproca em que se assenta a vida social.

Nessa perspectiva a educação decorrente do processo escolar imbricados na tríade escola-família-comunidade com vistas a aprimorar a aprendizagem em face de um diálogo igualitário, participativo e solidário, a gestão democrática baseada nos princípios da organização do trabalho pedagógico, sob as dimensões politica, social e pedagogia deve trilhar a dinâmica de funcionamento de seu trabalho, de modo a desenvolver estratégias que oportunizem a participação da família e da comunidade em prol do desenvolvimento de uma educação de qualidade para todas as crianças que ali estão. Para tanto, é preciso compreender as relações que a escola como um sistema conglomerado integrada a uma totalidade global estabelece com seu contexto social imediato, no que refere-se as atuais políticas de educação.

\section{O QUE DIZEM AS PROFESSORES, GESTORA E MÃES EM RELAÇÃO À PARTICIPAÇÃO DA FAMÍLIA NA ESCOLA}

A escola, a fim de desenvolver atividades meio, como medidas que intensifiquem a qualidade da educação e ensino oferecido às crianças no inicio de sua escolarização, tem buscado apoio em sua instância mais próxima: a família. Busca-se agora as principais dificuldades referente a relação Escola-Família-Comunidade em meio a realidade da escola 
pública pesquisada, e como esta organiza-se para superar tais impasses, alinhando as falas mais recorrentes dos sujeitos pesquisados, a partir de categorias de análises a discussão supracitada

Aponta-se nessa segunda parte dessa produção as instruções políticas e administrativas que regulam a gestão escolar da escola pública pesquisada. Falar do objeto de estudo EscolaFamília-Comunidade em sua avaliação institucional adequa a discussão a cerca das práticas que a referida escola pública trabalha e implementa para envolver a família na escola e na vida escolar do aluno e quais os impasses relativos a essa participação. Em busca de alcançar o objetivo investigativo que conduz o fio condutor dessa pesquisa, inicia-se a análise dos dados, embasados nas falas das professoras, gestora e mães de alunos sobre a realidade em que se dá a escola em termos de aproximação com a família e como a família se comporta diante de sua função social. O caráter qualitativo da pesquisa, permiti-nos uma análise sobre as principais dificuldades no que tange a participação família-comunidade na escola e no acompanhamento da rotina escolar dos filhos, tomando como referência as falas das professoras e gestora e as quatro mães colaboradoras na amostra dessa pesquisa.

\subsection{A FAMÍLIA-COMUNIDADE: ENCONTROS E ENTRAVES RELATIVOS À PARTICIPAÇÃO DEMOCRÁTICA NA ESCOLA PÚBLICA}

Elucidar os determinantes que encontram-se fora da escola, extrapola as atribuições e competências dos profissionais da educação, uma vez que os fatores externos que se concretizam como deficiência no não comparecimento às reuniões pedagógicas e no acompanhamento escolar dos filhos/filhas nas atividades de casa, por vezes se faz presente devido à falta de tempo dos pais frente ao trabalho que exercem, refletindo essa constatação nas suas condições objetivas de participação.

Para garantir o sustento da casa, a alimentação dos filhos, assegurar um espaço digno para viverem, muitos pais que pertencem a classe popular frente aos atropelos da sociedade pós-industrial passam a maior parte do dia em um ou mais empregos para receberem seus salários ou vencimentos a fim de suprir as necessidades mais básicas do cotidiano. De acordo com Paro (2008, p. 54), "mascarado por um sistema que os obriga a trabalhar, os pais vivem às voltas com dificuldades de toda natureza, lutando pela sobrevivência e sem condições até psicológicas para pensar nos problemas de ensino escolar". 
Amélia $^{1}$, uma das mães entrevistadas confessa que a responsabilidade para com a educação de seus filhos recai sobre sues compromissos, à medida que, por ter concluído as séries finais do ensino médio e seu cônjuge ter uma instrução escolar abaixo do seu nível de escolaridade. No entanto, como trabalha 40 horas semanais, quase não tem tempo para conferir essa instrução. Luna também afirma que trabalha como doméstica e aos sábados como diarista, seu marido, como diz ela, "é agricultor e mal tem tempo para estar em casa. Trabalhar é muito bom...mas, traz impossibilidades, que as vezes atrapalha nosso rendimento no acompanhamento com os filhos". Embora mantenham em suas condições objetivas de vida fatores que possivelmente formariam barreiras para a participação da família na escola, visto que as condições dadas a nível econômico da Família-Comunidade no Distrito no qual reside não serem favoráveis, esses não são destacados como impasses a interação da família-escola na intensificação da aprendizagem dos alunos. Nessa perspectiva a professora Sônia fala que "existe acompanhamento familiar de alguns pais que ajudam seus filhos nas atividades de casa ou os coloca em um reforço escolar. Mas infelizmente isso só acontece com a minoria... dificultando assim o aprendizado".

Empiricamente, quando não se conhece a realidade cotidiana que se dão no interior das casas e vivencias das pessoas, o primeiro critério ao ser definido pelas professoras é a falta de interesse dos pais. O que Paro (2008, p. 48) vem a discernir como condicionantes ideológicos de participação. Para o autor, "Essa visão negativa a respeito dos pais [...] pertencentes às camadas populares parece [...] disseminada em nossas escolas públicas de modo geral!”. A visão depreciativa que alguns pais possuem da escola, que por vezes soam em resposta ao descaso da escola ao tratar a relação escola-família-comunidade, gera um mal estar pedagógico na dimensão política entre a Comunidade Escolar. Assim os esforços coletivos na busca de melhores resultados na aprendizagem esbarram nas lacunas do trabalho pedagógico do professor, justificada pela omissão das famílias em suas atribuições mais diretivas.

São inúmeras as explicações que ouvimos frequentemente para justificar a ausência de aprendizagem decorrente do ensino segregador que as escolas historicamente realizam, ora pautadas em aspectos internos aos sujeitos, ora nas questões externas, relativas ao ambiente

\footnotetext{
${ }^{1}$ Pseudônimo de uma das professoras pesquisadas.
} 
(frequentemente às famílias dos estudantes). Quando dizemos que um aluno não aprende porque lhe falta motivação, porque é menos inteligente, porque tem menos capacidade, porque não tem apoio familiar, porque seu ambiente não é propício, apenas reforçamos um tipo de ação estratégica que culpa quem, na verdade, está sendo vitimado pelo sistema social, político, escolar, etc. (MELLO, 2011, p. 2).

A interlocução entre a escola e família que as mantem em laços imbrincados com os compromissos educativos dos educandos/filhos, encontram em meio a essas circunstâncias de competência e/ou desenvolvimento da aprendizagem por parte dos alunos cisões e divisões de responsabilidades, em que o peso de um ensino muitas vezes segregado assenta-se nas lacunas da ausência de participação pedagógica dos pais. Segundo a UNESCO (2009, p. 31) “[...] quando os alunos ficam indisciplinados ou têm baixo rendimento escolar, começam as disputas em torno da divisão de responsabilidades pelo insucesso".

É preciso tomar cuidado para não emergir dessa perspectiva, a redoma em que a família é tida como obstáculo impedindo que a função do professor se realize em sala de aula. Dessa forma não parece difícil perceber um anacronismo histórico em relação as atitudes dos professores em tratar de forma reducionista o interesse dos pais para com os estudos das crianças.

Assumindo os compromissos sociais da escola e da gestão escolar, não é mais da nossa época generalizar os fatores supracitados e tomá-los como verdades absolutas. O "até mesmo pela falta de interesse", discurso culturalmente elaborado na maioria das vezes nas falas dos professores e demais profissionais da educação quando questionados sobre a participação da família na escola, torna-se excessivamente frequente que não se atenta para outras prerrogativas. O que é difundido pelo senso comum não apenas pelos professores da escola cuja pesquisa foi desenvolvida, mas pela mãe Luna, que ao ser questionada sobre a participação da população que não pertencem ao conselho escolar afirma que o baixo percentual de presença nas reuniões se dá pelo fato de que os pais só procuram a escola tão somente quando existe alguma caso de indisciplina do filho, ou quando este é vitima de violência escolar por partes de outros alunos. Para a mãe Margarida os pais não têm interesse, tem uma concepção cultural depreciativa da escola dizem eu não! Ir para essa reunião fazer o que? Tenho que lavar roupa. 
Se existe escola, existe relação, mas a participação não é frequente e nem apresenta intencionalidade educativa por parte de determinados pais, nem tão pouco esta dentro das regulamentações do que é definido como participação na execução pedagógica. Na visão de Paro $(2008$, p.47) [...] "se estamos interessados na participação da comunidade na escola, é preciso levar em conta a dimensão em que o modo de pensar e agir das pessoas que aí atuam facilita/incentiva ou dificulta/impede a participação dos usuários”. Neste contexto,

percebemos [...] que geralmente o processo escola-família é desencadeado sem os devidos e desejáveis cuidados preliminares: é muito comum os sistemas de ensino e escolas partirem direto para a negociação/cobrança de responsabilidades das famílias, antes de compreenderem as condições dos diversos grupos de familiares dos alunos (UNESCO 2009, p. 16).

Esse discurso de um rendimento "satisfatório e êxito" na aquisição da aprendizagem dos alunos que advém das classes populares em face da participação processual do ato de fazer da família na vida escolar do filho acaba sendo tomado como parâmetro em muitas instituições públicas, responsabilizando a família pelo desenvolvimento não satisfatório dos alunos, já que estes não participam ativamente das atividades escolares de seus filhos/filhas. Haja vista que,

[...] o insucesso escolar deveria suscitar a análise de causas dos problemas que interferiram na aprendizagem, avaliando o peso das condições escolares, familiares e individuais do aluno. O que se consta é que, em vez disso, o comportamento mais comum diante do fracasso escolar é a atribuições de culpas, que geralmente provoca o afastamento mútuo (UNESCO 2009, p.31).

Para essa reflexão, toma-se o conhecimento do contexto social do aluno, o que esta interferindo na aprendizagem do educando, para não ter que responsabilizar a família por resultados insatisfatórios de ensino. O diálogo sob esse ponto de reflexão toma as ações dos professores/professoras, gestores/gestoras a entenderem e ouvirem as famílias sobre os motivos que causam a ausência na escola e por que os filhos não trazem os deveres de casa.

Nesse contexto, às vezes, centra-se tanto no número de produções que estabelecem projetos e medidas de interação com as famílias que perguntas básicas como as supracitadas 
ficam encobertas no ordenamento e busca de soluções inovadoras para as cisões que formamse na escola, na direção da superação desses impasses de dicotomia Escola-Família.

Na escola cuja pesquisa foi desenvolvida Piedade e as demais educadoras participantes desse estudo compreendem que a relação da escola com a família sucinta em uma estratégia peculiar ao alcance do que é proposto desde a primeira Conferência Mundial em Juntiem (realizada na Tailândia, de 5 a 9 de março de 1990) e reafirmada em Dacar (realizada no Senegal, em 2000). Seus posicionamentos conferem total dependência de uma cultura de participação para a intensificação da aprendizagem dos alunos nos anos iniciais.

Isto fica demarcado quando da afirmativa:

eu compreendo que há uma necessidade de existir essa parceria da escola da família e da comunidade... porque assim facilita o processo de desenvolvimento educacional... no ambiente escolar, há uma necessidade de existir essa parceria então a escola, o ambiente precisa pensar em estratégias que mantenham esse vinculo mais acirrado. Porque a gente sabe... que não têm, não temos cem por cento de frequência dos pais na escola, isso não acontece ainda... então é preciso que a escola promova eventos pense em alguma coisa que envolva a escola a família e a comunidade....porque assim vai melhorar o desenvolvimento da escola da aprendizagem dos alunos. (Professora Maria de Lurdes).

A busca por uma gestão participativa é um processo autônomo que exige de quem a procura a plenitude de suas competências, enquanto propriedade da função educativa. É o que revela-se na perspectiva sociocrítica citada por Libâneo (2011, p.295), cuja "a organização significa valorizar ações concretas dos profissionais na escola que sejam decorrentes da sua iniciativa, de seus interesses, de suas interações (autonomia e participação), em razão do interesse público dos serviços prestados" [...], explicitando nesse contexto sua função educativa específica.

3. AS PRÁTICAS DE INTERAÇÃO ENTRE A ESCOLA MATOS DE LUCENA E FAMÍLIA DO DISTRITO DE FELIZARDO EM FUNÇÃO DE ESTRATÉGIAS DE APRENDIZAGEM NOS ANOS INICIAIS 
Embasadas nessa abordagem de autonomia, em que o cenário do objeto de estudo na escola base da pesquisa dessa produção requer uma maior organização em termos de práticas comunicativas, as iniciativas de aproximação que a instituição desenvolve para integrar a família relaciona-se em meio a um quadro de categorização com os ciclos de eventos. Eventos que por vezes são confundidos com projetos.

Bem os projetos que...sempre tem são os relacionados a feira de afrodescendentes, feira de ciências, são os eventos que toda a comunidade faz parte, os pais, né?...os alunos ficam bastante empolgados com esses eventos e... tem outros eventos que a escola, né? procura melhorar a aprendizagem do aluno que são o luz do saber que levam aqueles alunos que tem dificuldade para fora da sala de aula, para um espaço mais adequado a aprendizagem (Professora Maria de Lurdes).

A escola... ela desenvolve...promove eventos anuais. Durante todo o ano a escola promove a festa da páscoa que tem até a encenação da via sacra onde é aberta ao publico os pais participam as famílias. Tem também as festas juninas, o folclore e sempre comemora o dia dos pais, o dia das mães dando a oportunidade pra que todos estejam lá, socializem, vejam, conheçam o ambiente escolar onde os seus filhos estudam $e$ conheçam também o grupo gestor, coordenador professor, todos que trabalham na escola. Eh... só acontece esses eventos relacionados as datas comemorativas... (Professora Confiança).

Para a gestora da escola pesquisada a realização dos eventos reúne em torno de $85 \%$ dos pais. Segundo Piedade ${ }^{2}$ os pais gostam mais dos eventos do que das reuniões, não seria o caso de integrar nos eventos a intencionalidade das ações educativas, apresentar aí as propostas de melhorias que a escola futuramente venha a desenvolver? Talvez a inovação seja esta, caberia a ideia de política de interação ou projeto justamente nesse ponto, considerando que o projeto é de natureza extremamente relacionado com as especificidades da escola e por ela elaborado e implementado. Uma vez que,

\footnotetext{
${ }^{2}$ Pseudônimo da gestora
} 
uma política [...] de interação escola-família é uma forma de estabelecer uma racionalidade produtiva para essa delicada relação, de modo a tirá-la tanto do lugar de bode expiatório [...] quanto do otimismo ingênuo __ segundo o qual basta haver vínculos amistosos entre professores, gestores, mães, avós e demais parentes para se julgar que há complementaridade entre os dois universos de referência das crianças (UNESCO 2009, p. 42).

Seria necessário já que em unanimidade, todos reconhecem e compreendem a relevância dessa interação para a intensificação da aprendizagem dos alunos nas dimensões individual e social uma participação nas tomadas de decisão para que todos possam ser ouvidos com maior frequência, abrir espaços para que essa participação aconteça de fato. $\mathrm{Na}$ perspectiva de Paro $(2008$, p.27) "[..] a luta pela participação coletiva e pela superação dos condicionantes deve compor um só processo, de modo que avanços em um dos campos levem a avanços no outro, de forma contínua e interdependente".

Em consonância a essa sistemática, a escola pública vincula-se ao necessário aperfeiçoamento dos processos de organização da gestão participativa cabendo à instituição integrar a participação dos pais e da comunidade nos interesses sócio-educacionais da dinâmica de escolarização de seus discentes, a partir de projeções de uma formação individual e social, essencialmente, referencializada por visão educativa que passa por uma gestão democrática, presente e com iniciativas de cunho político frente ao fato de fomentar competências de participação e de encontro - sempre num continuum da interação EscolaFamília. O que fortalecerá os resultados das práticas organizacionais e administrativas para a sociedade pós-industrial que, necessariamente, precisa incorporar e aprender a priorizar a negociação e o direito de participação ativa da família nos processos de tomada de decisão para além da escola, nos rumos de desenvolvimento de seus contextos e modos de vida; por exemplo.

\section{CONSIDERAÇÕES FINAIS}

Para garantir o direito que as crianças, em seus primeiros anos de escolarização, têm em relação à aprendizagem na perspectiva da gestão participativa, especialmente, aqui concebido, a escola como instância institucional e legal busca, ao longo das últimas décadas, 
através de mecanismos internos e políticos, subsídios a sua prática pedagógica vinculada fundamentalmente ao desempenho e rendimento acadêmico discente. Isto se dá, concomitantemente, ao passo que caminhamos em direção a um contexto multifacetado de aprendizagem, quer sejam referencializados pelo mercado de trabalho, e ela perspectiva prioritária de cidadania ou de outros referenciais de formação humana, dada competências e habilidades específicas. Para tanto, por qualquer via, é imprescindível contar com o apoio da família nesse processo de parceria formativa.

Há um consenso acerca da necessidade de superação, crescente, das inúmeras dificuldades estruturais de tempo e preparação, da família, na correspondência das demandas do processo de escolarização de seus dependentes. É nesse contexto que a questão de pesquisa, desse estudo pode ser respondida, que foi: "De que modo a escola pública pode articular a relação escola-família-comunidade em função das estratégias de aprendizagens discentes nos anos iniciais?", pode ser respondida a partir dos achados dessa investigação. E esta resposta parte do fato de que a escola deve estrategicamente, sistematicamente e duradouramente, estimular e conceber a família como membro constituinte das relações, ações, decisões, reuniões e planejamentos estabelecidos na busca de soluções para resolução das dificuldades mais imediatas da instituição, garantindo uma boa educação e aprendizagem dos educandos nos anos iniciais. Isso, inclusive, no processo de acompanhamento do rendimento escolar de seus dependentes.

Este estudo teve a intenção de investigar quais às práticas de interação que a escola pública implementa em sua rotina diária para envolver politicamente a família em sua gestão, tendo em vista bons resultados na aprendizagem dos alunos nos anos inicias. Assim, identificado o quadro atual que encontra-se o ordenamento de iniciativas na e para essa relação delicada com a família, fez-se necessário estabelecer algumas estruturas favorecedoras do diálogo. Pois, as práticas dialógicas podem conferir maior organização para a participação política e operacionalização nos resultados de aproximação de uma boa base de formação humana preconizadas, no coletivo docente e não-docentes, pelas escolas.

Iniciar um trabalho de aproximação para com a família é algo complexo e não pelo fato de está no escopo das responsabilidades legais do contexto da gestão institucional da escola, mas por exigir dos profissionais atentos a essa relação escola-família a compreensão sobre o contexto social de formação do discente, na base do necessário fortalecimento da 
gestão participativa e do diálogo como elementos que venham a consolidar o planejamento pedagógico nos coletivos de co-gestão.

No decorrer dessa produção destacou-se uma discussão sobre a relevância da relação da escola com a família em seus aspectos mais executivos, aos mais reflexivos, que não estão, no geral, incorporados em primeiro momento na participação pedagógica que se tem hoje, comumente, nas escolas. Esta carência agrava as adversidades latentes da interação-escolafamília frente aos condicionantes de organização do trabalho pedagógico nas unidades escolares.

O desafio dessa necessária interação está, fundamentalmente, no como adequar a dinâmica de funcionamento interno da escola em relação às buscas de ser, a escola, mais próxima da família no processo de construção de base valorativa e formativa para a escola, para os educandos e, porque não, para as próprias famílias. Inicialmente, em suas estruturas possíveis no processo de edificação de interações necessárias tiradas desse coletivo da gestão da aprendizagem, a partir da escola.

A nova família e o novo aluno do século XXI trazem à tona uma série de dificuldades na e para a manutenção da relação escola-família. Na direção desses ajustes necessários a escola pode tomar como pauta de início dos trabalhos, os planejamentos advindos das estruturas já existentes de festividades civis que, por sua vez, já carecem da participação política da comunidade escolar; canalizando assim esforços coletivos para determinados fins de aproximação e integração. Isso implica em mudanças de concepções de gestão e co-gestão de ordem operacional e administrativa.

Romper com uma cultura que discursa a prática dialógica e estabelece ações neocolonialistas é um processo que não tira do centro educativo e pedagógico a autoridade e proficiência de quem estar coordenando o trabalho coletivo, mas acrescenta à sua administração novos atores sociais, que integram o seu campo com informações e sugestões relevantes sobre os alunos. Incorporando, assim, a educação pela integralidade da ação político-pedagógica. Para isso, as políticas contemporâneas, os conhecimentos sobre a gestão e o diálogo devem estar como medida da atividade-fim da instituição escolar frente as crescentes demandas por aprendizagem discente.

Cabe agora cada escola adequar as práticas dialógicas nas reuniões o conhecimento sobre quantas famílias se fizeram ausentes e em consenso professores/professoras, 
gestor/gestora desenvolver ações de aproximação que favoreçam resultados em curto, médio e longo prazo.

A visita domiciliar é uma alternativa nesse cenário. E, por sua vez, não é uma proposta inovadora. Quando tratamos da relação escola-família-comunidade, a inovação está no tratamento das informações obtidas durante o processo de conhecimento da realidade do aluno. Nessa direção, o conhecimento relativo à gestão participativa é apenas o primeiro passo em direção ao que se fazer, por que fazer e como se fazer.

\section{REFERÊNCIAS}

BORDIGON, G.; GRACINDO, R.V. Gestão da educação: o município e a escola. In: FERREIRA, N.S.C; Aguiar, M. A. da S. Gestão da educação: impasses, perspectivas e compromissos. São Paulo. Ed: Cortez, 2004, p. 147.

BRASIL. Senado Federal. Lei de Diretrizes e Bases da Educação Nacional: n 9394/96. Brasília: 1996. Disponível em:< http://portal.mec.gov.br/arquivos/pdf/ldb.pdf. Acessado em: 10 de Nov. de 2015.

FREITAS, Dirce Nei Teixeira. A gestão educacional na interseção das políticas federal e municipal. In: Rev. Fac. Educ. vol.24 n.2 São Paulo July/Dec. 1998. Disponível em: http://dx.doi.org/10.1590/S0102-25551998000200003 Acesso em: 12 de Dez. de 2015.

LIBANÊO, José Carlos. Educação escolar: políticas, estrutura e organização. São Paulo. 10 ed: Ed. Cortez, 2011.

MELLO. Roseli Rodrigues. Comunidades de aprendizagem: democratização dos centros educativos. In: Revista Tendências Pedagógicas. 2011. Disponível em:< http://www.comunidadedeaprendizagem.com/uploads/materials/46/7eacb2e7563cc108c1f850 dc1fff60f2.pdf. Acesso em 07 de Ago. de 2015.

PARO, Vitor Henrique. Gestão Democrática na Escola Pública. São Paulo. Ed. Ática, 2008.

UNESCO. Interação escola família: subsídios para práticas escolares. CASRTO, Jane Margareth; REGATTIERI, Marilza (org). Brasília, 2009. Disponível em:< http://portal.mec.gov.br/index.php?option=com_docman\&view=download\&alias=4807escola-familia-final\&Itemid=30192 Acesso em: 29 de Dez. de 2015. 